\title{
Effect of Cooling Rate and Aluminium Addition on Graphite Growth during Solidification and Graphitization
}

\author{
Jacques Bourdie ${ }^{1,2, a}$, Fabien Bruneseaux ${ }^{2, b}$, Philippe de Parseval ${ }^{3, c}$, \\ Sophie Gouy ${ }^{3, d}$, Lydia Laffont ${ }^{1, e}$ and Jacques Lacaze ${ }^{1, f}$ \\ ${ }^{1}$ CIRIMAT, Université de Toulouse, CNRS, INPT, UPS, 4 allée Emile Monso CS 44362, \\ 31030 Toulouse Cedex 4, France \\ ${ }^{2}$ Saint-Gobain PAM, Les Longues Raies BP 109, 54704 Pont-à-Mousson Cedex, France \\ ${ }^{3}$ Centre de Microcaractérisation Raimond Castaing, Université de Toulouse, \\ UPS - CNRS - INPT - INSA ; UMS 3623, 3 rue Caroline Aigle, 31400 Toulouse, France \\ a*jacques.bourdie@ensiacet.fr, bfabien.bruneseaux@saint-gobain.com, \\ cphilippe.deparseval@ums-castaing.fr, 'sophie.gouy@ums-castaing.fr, \\ elydia.laffont@ensiacet.fr, jacques.lacaze@ensiacet.fr
}

Keywords: graphite growth, spheroidal graphite, degeneracy, aluminium, magnesium, cooling rate.

\begin{abstract}
Even using high inoculation levels, mottled structures are often obtained when casting Mg-treated cast irons in thin wall parts. For full graphitization of the cast components, this calls for a subsequent heat-treatment which is generally achieved in the austenite field. The aim of this work was investigating the impact of the process and the cooling rate on the graphite structure for two different casting conditions. The influence of the cooling rate on graphite degeneracy due to the presence of impurity was also investigated considering low-level additions of aluminium. Extensive metallographic investigation has been carried out from which it is concluded that the internal graphite structure is the same for the two studied cooling conditions. Accordingly, the growth mechanism of graphite should be the same when it precipitates from liquid, during eutectic reaction or else solid-state graphitization. Finally, microanalyses suggest magnesium and aluminium do not interact in the same way with graphite during its growth.
\end{abstract}

\section{Introduction}

Ensuring a correct microstructure in all parts of a casting may be an issue for foundry men when the component has thin and heavy sections that define very different solidification conditions. Such changes in cooling conditions involve large variations in undercooling for nucleation and early growth of graphite from the liquid and during eutectic reaction, as well as differences in solid-state precipitation of graphite after solidification has been completed. This work was intended to comparing the formation of graphite in alloys cast both in thin section obtained by centrifugation and in sand mould. Centrifugation generated a mottled (partly stable and partly metastable) structure and was followed by a heat-treatment in the austenite field to decompose cementite. This latter step results in significant solid-state graphite growth. Solidification in sand mould fully processed in the stable system and was followed by a slow cooling that led to limited solid-state graphite growth.

In the same line, the effect of cooling rate on the impact of impurities was considered as it is known that the tolerance level increases with cooling rate. A transition within the investigated range of cooling rates would thus give some insight in graphite growth mechanisms. Aluminium - which is reported as a vermicular graphite promoter [1-5] - was selected because it affects graphite shape above a critical level which is within the capabilities of modern means for microanalysis. 


\section{Experimental Procedures}

The melts were prepared in a $250 \mathrm{~kg}$ induction furnace using pig iron and adjusting the silicon content by adding FeSi75 in the furnace to reach a final content in silicon around $2 \mathrm{wt} \%$ (after treatment and inoculation). After superheating to $1500^{\circ} \mathrm{C}, 30 \mathrm{~kg}$ of melt were poured into a ladle for nodularizing treatment with FeSiMg and addition of pure aluminium when necessary. The addition of FeSiMg was higher for the melts used for the sand-mould reference castings than for those used for thin wall castings.

For the reference fully graphitic mould castings, the melt was poured in $2.5 \mathrm{~kg}$ blocks with cavities for two plates $\left(18 \times 14.5 \times 180 \mathrm{~mm}^{3}\right)$ dedicated to metallographic investigations. Inoculation was performed by depositing a commercial inoculant at the bottom of the mould $(0.2 \%$ of the weight of the casting). A thermocouple was inserted to record the temperature evolution of the alloy during solidification and cooling which indicated that the solidification time was about $2 \mathrm{~min}$. Three melts were prepared with increasing amount of aluminium, denoted R1-R3 in the following.

The second type of castings was realized through centrifugal casting on a laboratory-scale facility. For each pipe, some melt from the ladle was poured in a mobile spoon for distributing the melt inside the rotating die. Inoculation was realized by depositing the commercial inoculant on the inner surface of the mould before pouring the melt. The pipe thickness was $3 \mathrm{~mm}$ with a solidification time of about 3-4 seconds. Because of the high cooling rate the as cast structure of the samples was mottled and a subsequent heat-treatment was carried out for graphitization in the austenite field which was followed by controlled cooling for obtaining a fully ferritic final microstructure. Three melts, denoted $\mathrm{C} 1-\mathrm{C} 3$ in the following, were again prepared with amounts of aluminium intended to be close to those of the first series.

Chemical analyses of all six melts are listed in Table 1. Carbon and sulphur were measured on the base melt by infrared spectroscopy. Silicon and all other elements were quantified on the samples by, respectively, gravimetric method and inductively coupled plasma (ICP) spectroscopy after acid dissolution. The alloys contained also 0.029 to $0.032 \mathrm{wt} . \% \mathrm{Ni}$ and 0.059 to $0.061 \mathrm{wt} . \% \mathrm{P}$. As seen in table 1, the Mg addition was larger for sand mould casting than for centrifugal casting in order to ensure a spheroidal growth of graphite even with a lower cooling rate.

Table 1. Chemical composition of the alloys in wt.\% (bal. Fe).

$\mathrm{R}$ and $\mathrm{C}$ stand for reference and centrifugal castings respectively.

\begin{tabular}{|c|c|c|c|c|c|c|c|c|c|c|c|}
\hline & $\mathbf{C}$ & $\mathbf{S}$ & $\mathbf{S i}$ & $\mathbf{M g}$ & $\mathbf{A l}$ & $\mathbf{T i}$ & $\mathbf{C r}$ & $\mathbf{C u}$ & $\mathbf{M n}$ & Mo & $\mathbf{V}$ \\
\hline R-1 & 3.85 & 0.014 & 1.91 & $\mathbf{0 . 0 2 5}$ & $\mathbf{0 . 0 1 2}$ & 0.031 & 0.035 & 0.052 & 0.198 & 0.008 & 0.007 \\
\hline R-2 & 3.85 & 0.014 & 1.94 & $\mathbf{0 . 0 2 4}$ & $\mathbf{0 . 1 1 2}$ & 0.029 & 0.035 & 0.052 & 0.194 & 0.008 & 0.004 \\
\hline R-3 & 3.85 & 0.014 & 2.09 & $\mathbf{0 . 0 2 4}$ & $\mathbf{0 . 2 2 1}$ & 0.027 & 0.035 & 0.053 & 0.194 & 0.007 & 0.003 \\
\hline C-1 & 3.85 & 0.014 & 1.92 & $\mathbf{0 . 0 1 0}$ & $\mathbf{0 . 0 0 6}$ & 0.035 & 0.028 & 0.053 & 0.154 & 0.006 & 0.006 \\
\hline C-2 & 3.85 & 0.014 & 1.95 & $\mathbf{0 . 0 1 2}$ & $\mathbf{0 . 1 0 1}$ & 0.035 & 0.029 & 0.054 & 0.154 & 0.006 & 0.004 \\
\hline C-3 & 3.85 & 0.014 & 2.00 & $\mathbf{0 . 0 1 0}$ & $\mathbf{0 . 2 0 1}$ & 0.035 & 0.029 & 0.054 & 0.157 & 0.006 & 0.003 \\
\hline
\end{tabular}

A standard metallographic preparation was used for optical microscopy (OM) and scanning electron microscopy (SEM) observations. When necessary, the samples were etched in 5\% Nital solution (5\% nitric acid in ethanol) to reveal the matrix structure and deep etching was performed with a dilute nitric solution $\left(25 \mathrm{~mL}\right.$ of $\mathrm{HNO}_{3}$ at $65 \%$ in $50 \mathrm{~mL}$ of distilled water) to observe the graphite surface and its 3D structure.

Electron probe micro-analyses (EPMA) were performed in spot mode using a CAMECA SXFive FE operated with the following parameters: accelerating voltage $10 \mathrm{kV}$, beam current $50 \mathrm{nA}$ and a counting time on peak of $40 \mathrm{~s}$ for $\mathrm{Al} \mathrm{K} \alpha$ and $\mathrm{Mg} \mathrm{K} \alpha$. The background was measured on both sides of every peak during $20 \mathrm{~s}$. With these conditions, the detection limit for light elements such as $\mathrm{Mg}$ and Al was $75 \mathrm{ppm}$. Though the diameter of the electron beam is $100 \mathrm{~nm}$, the interaction of the beam and the material defines a pear-like volume which has a diameter of about $1.5 \mu \mathrm{m}$ in graphite. 
Some secondary ion mass spectroscopy (SIMS) analyses were also carried out in the mapping mode using a CAMECA IMS-7f. $\mathrm{O}^{2+}$ was used as primary beam with an accelerating voltage of $15 \mathrm{kV}$ and a current of $130 \mathrm{pA}$. Size of analysed surfaces varies between $15 \times 15$ and $50 \times 50 \mu \mathrm{m}^{2}$ with a picture resolution of $256 \times 256$ pixels. Each map corresponds to twenty cycles with a counting time of $5 \mathrm{~s}$ for ${ }^{24} \mathrm{Mg}$ and $1 \mathrm{~s}$ for ${ }^{27} \mathrm{Al}$. Concentration profiles have also been plotted from the records.

\section{Results}

No aluminium addition. The first samples of each type of casting (R-1 and C-1) were without Al addition. Fig. 1 illustrates the graphite morphology in the as-cast state for both castings and after graphitization for the centrifugal casting. As expected, the sand mould casting is fully graphitic and exhibits a classical structure of spheroidal graphite consisting in sectors radiating from the centre (Figs. 1-a and 1-d) with an average nodule diameter of about $30 \mu \mathrm{m}$. In the as-cast centrifuged sample, the graphite formed during solidification is also spheroidal but, due to the high cooling rate, the particles are much smaller in size with an average diameter lower than $10 \mu \mathrm{m}$ (Figs. 1-b and 1e). The graphite observed in the heat-treated centrifuged sample, which has mostly grown during solid-state graphitization, is also spheroidal with the same internal structure composed of sectors (Figs 1-c and 1-f).
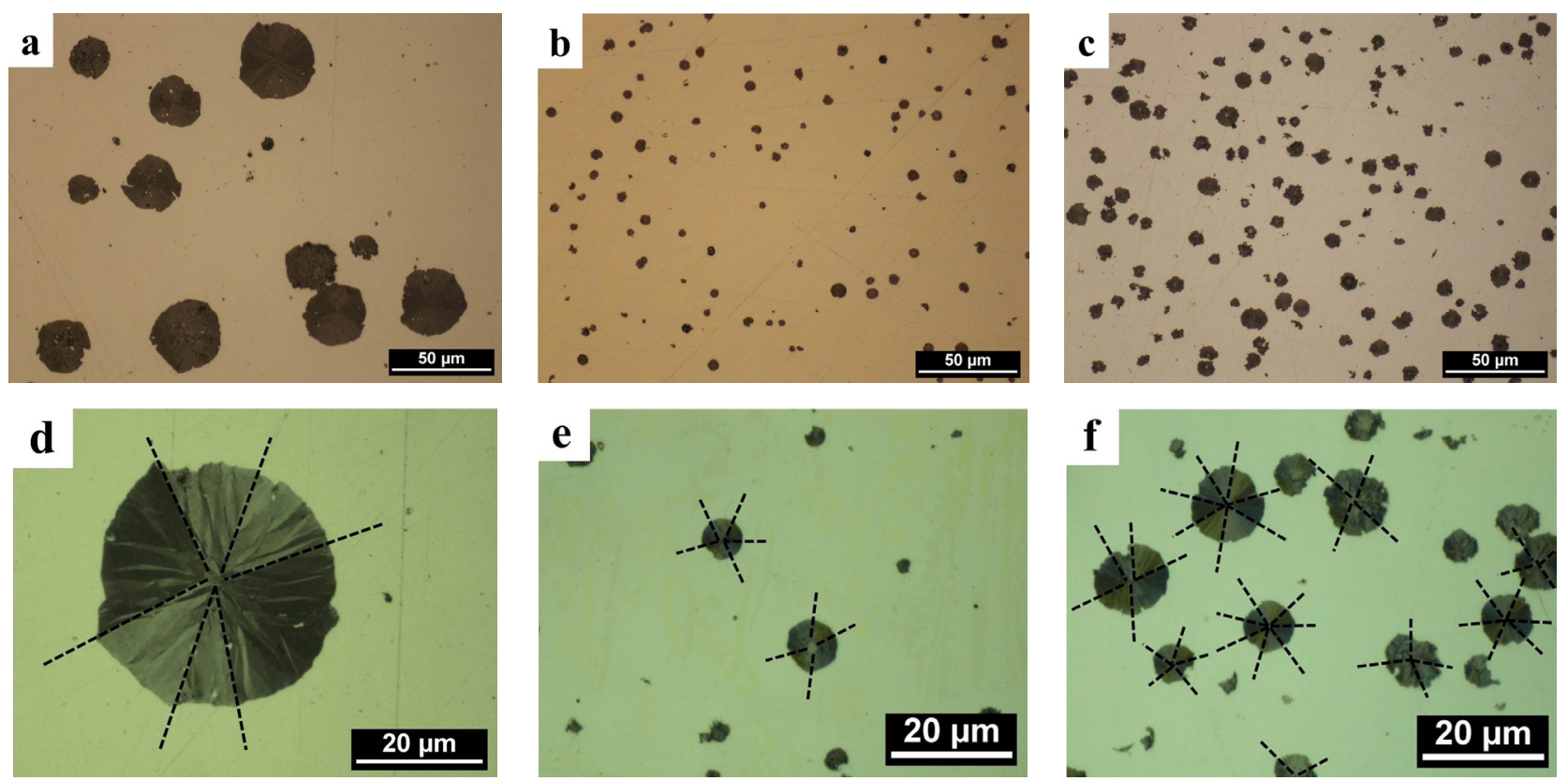

Figure 1. Optical micrographs showing the graphite morphology in castings with no aluminium addition: reference casting R-1 (a and d), as cast centrifuged sample C-1 (b and e) and heat-treated centrifuged casting $\mathrm{C}-1$ (c and $\mathrm{f}$ ). In the bottom row, interrupted lines underline sectors in graphite nodules.

SEM observations were also conducted after deep etching in order to observe the surface appearance of the different graphite particles as illustrated in Fig. 2 for as-cast alloys R-1 and C-1. Sample R1 shows the so-called cabbage leaf appearance for which the outer layers of graphite are elongated along their prismatic directions and are enveloping the nodule surface. In Fig. 2-b, a nodule is seen encased in a network of eutectic cementite. Interestingly enough, the surface of the nodules of the centrifuged sample in the as-cast state appears much smoother than in the R-1 sample. 

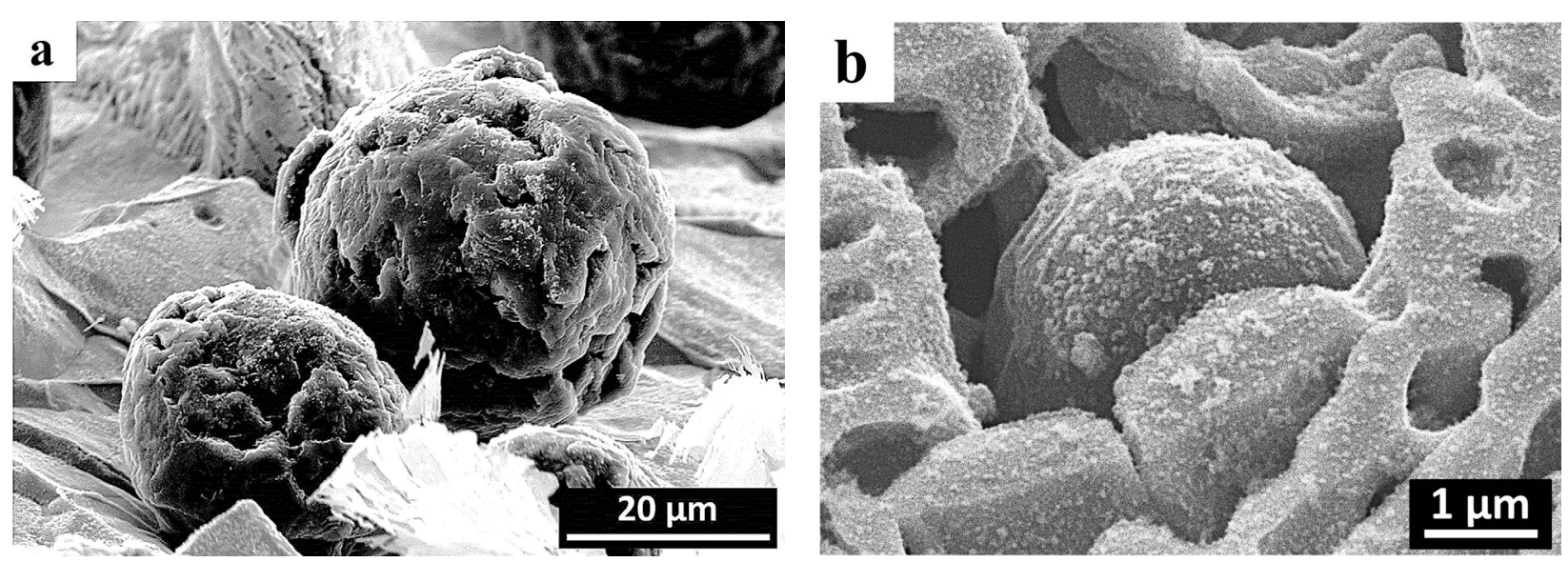

Figure 2. SEM observations after deep etching of R-1 alloy (a) and of as-cast C-1 alloy (b).

Fig. 3-a shows nodules in deep etched heat-treated C-1 alloy and Fig. 3-b presents both the polished section and the surface of two neighbouring nodules of the same sample. The outer surface of these nodules present a cabbage-leaf aspect which is similar to that in Fig. 2-a. It can be concluded that the smooth surface of the graphite nodules of the centrifuged material in the as-cast state (Fig. 2-b) has evolved to ressemble the outer surface of the R-1 sample (Fig. 2-a) during solid-state graphitization. It is further clearly seen with Fig. 3-b that the cabbage leaf morphology only concerns the outer surface of the nodules and has very little to do with the internal structure of the nodules where graphite is seen to be compact.
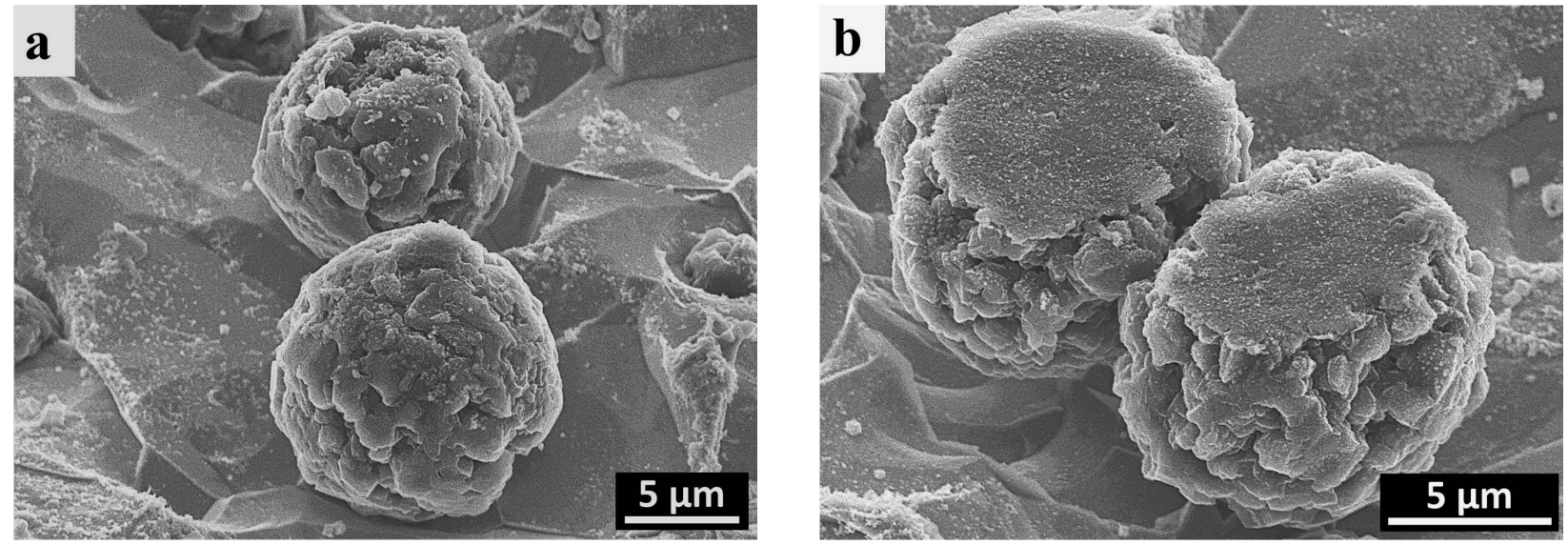

Figure 3. SEM observations after deep etching of heat-treated C-1 alloy.

Associating these OM and SEM observations with TEM observations conducted by Theuwissen et al. [6,7] and Jday et al. [8] suggests that the growth mechanism of spheroidal graphite is the same during solidification - directly from the melt as well as a result of the eutectic transformation - and during graphitization by solid-state decomposition of cementite. Furthermore, the cooling rate does not appear to affect the growth mechanism of graphite itself.

Microstructure after aluminium additions. Two levels of aluminium addition were used for both reference and centrifugal castings, respectively about 0.1 and 0.2 wt.\% (see Table 1). Fig. 4 compares graphite shape as observed in the samples without and those with the two levels of aluminium. In the reference sand mould castings, the addition of aluminium leads to significant graphite degeneracy marked by an important presence of vermicular graphite. This effect increases with the aluminium content.

Concerning the centrifuged samples, there is not such impact of aluminium addition on graphite shape. The as-cast structure remains mottled with well-formed spheroidal graphite particles. Furthermore, aluminium does not affect graphite growth during heat-treatment as all samples exhibit the same microstructure: the graphite appears fully spheroidal without any trace of 
vermicular graphite. These observations confirm that high cooling rate during solidification promotes spheroidal growth of graphite, thus confirming that the harmful threshold of elements like aluminium increases with cooling rate as reported by Fargues and Margerie [5]. It is however very striking that aluminium has no effect on graphite growth during graphitization.
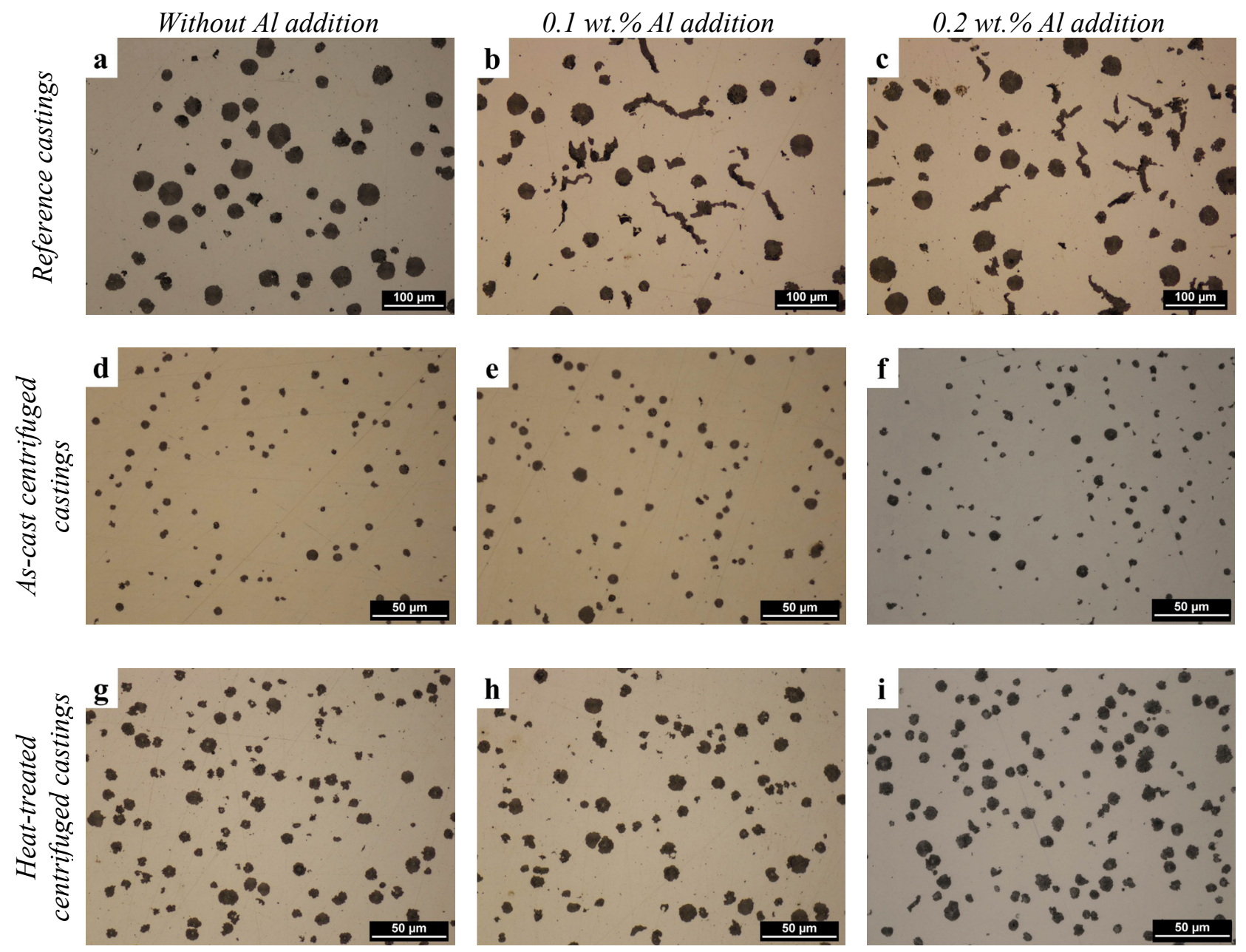

Figure 4. OM micrographs for comparison of the microstructure of: i) reference castings without aluminium addition (a) and with $0.1 \mathrm{wt} . \%$ (b) and $0.2 \mathrm{wt} \%$ (c) aluminium addition; ii) as cast centrifuged castings without (d) and with 0.1 wt.\% (e) and 0.2 wt.\% (f) aluminium addition; and iii) heat-treated centrifuged castings without $(\mathrm{g})$ and with $0.1 \mathrm{wt} . \%(\mathrm{~h})$ and $0.2 \mathrm{wt} . \%$ (i) aluminium addition.

Study of aluminium and magnesium distribution. EPMA analyses were realized on the reference and heat-treated centrifuged castings with $0.2 \mathrm{wt} \%$ (R-3, C-3) and without (R-1, C-1) aluminium addition. Measurements were realized in spot mode along profiles through graphite particles to look at the aluminium and magnesium distribution across the graphite/matrix interface. Fig. 5 shows the case of a nodule in the C-3 sample and Fig. 6 that of a worm in the R-3 sample. The size of the circles on the graphs corresponds to the diameter of the interaction volume between the beam and the material.

EPMA profiles showed a much higher aluminium content in the matrix than in graphite and no accumulation at the interface was noted. Peaks of magnesium content could be sometimes observed in the middle of the graphite nodules (e.g. Fig. 5) that relate to nuclei. More importantly, a magnesium peak was observed for some graphite/matrix interfaces as illustrated in Figs. 5 and 6. This was not systematic and Table 2 lists the number of interfaces where a peak of magnesium was observed as function of the number of analysed interfaces for each sample. These measurements have to be considered with caution because of their position at the interface and the important difference of characteristics between graphite and ferrite. Nevertheless, several arguments suggest 
that such peaks do actually correspond to an accumulation of magnesium at the interface: i) they were not observed for any other trace element during these experiments and in particular aluminium; ii) except the points corresponding to the nuclei, the peaks are the only measurements above the detection limit and it is a recurrent observation though not being systematic.
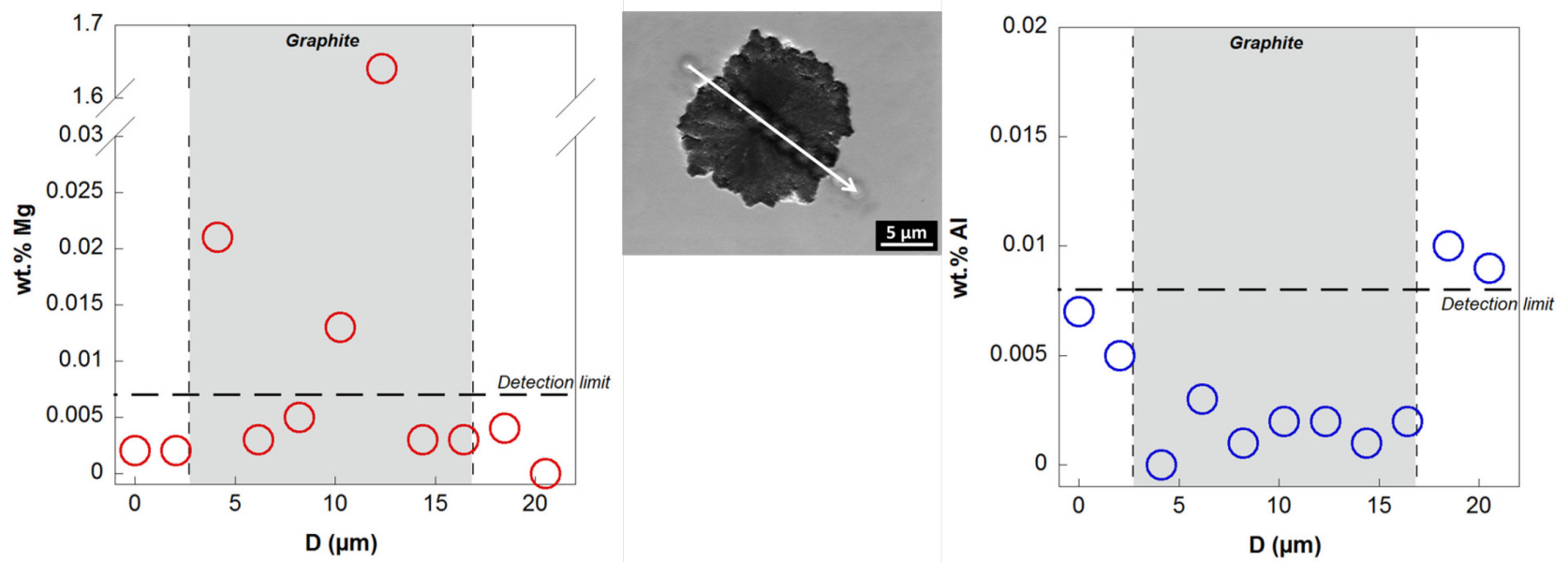

Figure 5. SEM observations and concentration profiles of magnesium and aluminium across a nodule of sample C-1. The size of the circles corresponds to the diameter of the interaction volume between the beam and the material. Note the change in scale of $\mathrm{Mg}$ measurements.
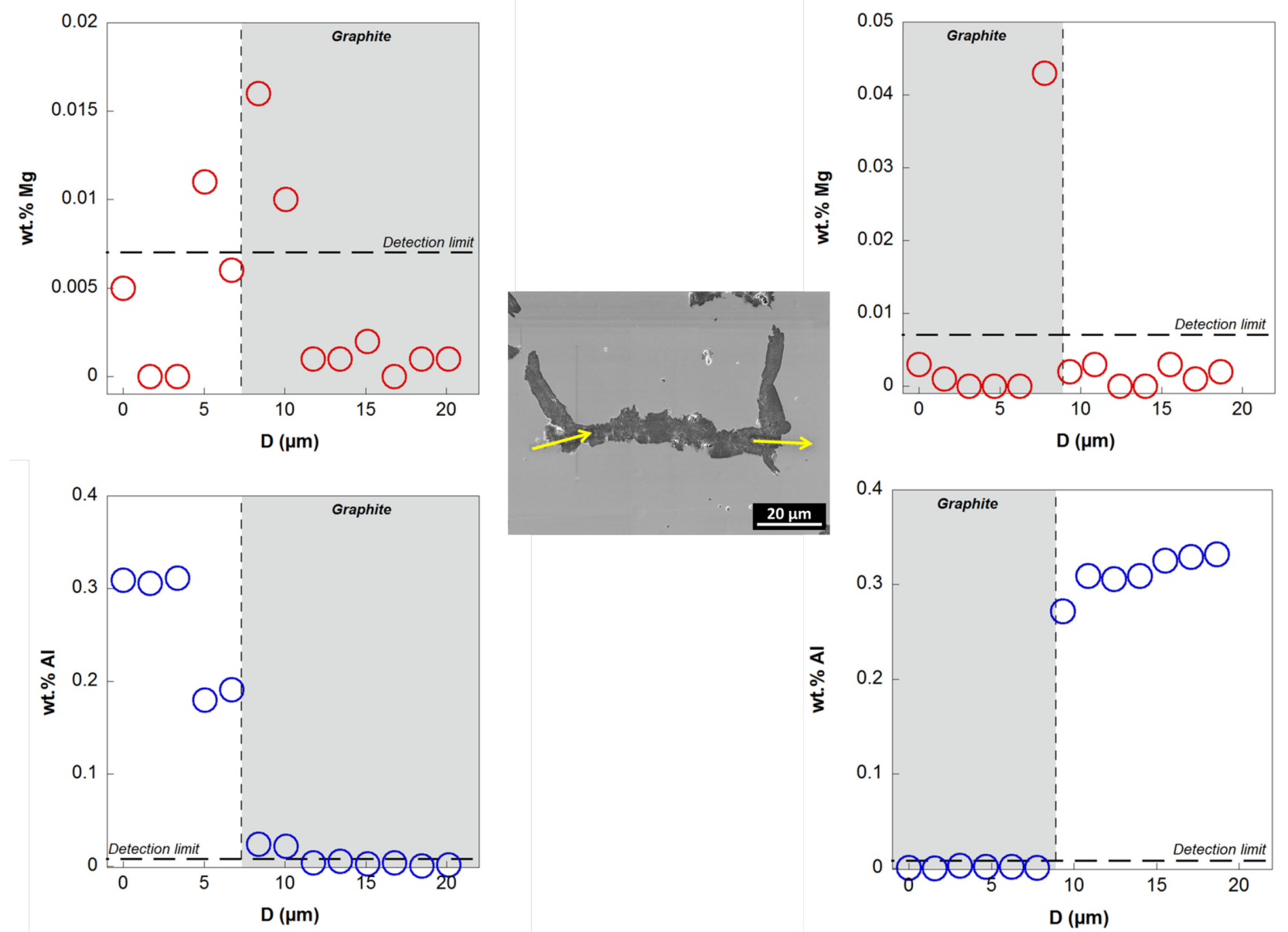

Figure 6. SEM observations and concentration profiles of magnesium and aluminium on a degenerated graphite particle of sample R-3. The size of the circles corresponds to the diameter of the interaction volume between the beam and the material. 
Table 2. Number of interfaces showing a peak in magnesium concentration and total number of analysed interfaces (between brackets) for each sample and shape of graphite.

\begin{tabular}{|c|c|c|}
\hline & nodules & vermicular graphite \\
\hline R-1 & $3(14)$ & - \\
\hline R-3 & $6(12)$ & $5(6)$ \\
\hline C-1 & $5(16)$ & - \\
\hline C-3 & $7(16)$ & - \\
\hline
\end{tabular}

These observations are in agreement with SIMS analyses performed on another centrifuged sample for which many poisoning elements were added to the melt. This sample presents the same base composition as the previous castings with the following changes: $0.015 \mathrm{wt} . \% \mathrm{Mg}, 0.318 \mathrm{wt} . \%$ Al, 0.175 wt. $\%$ Ti, 0.009 wt.\% Sb, 0.020 wt.\% Sn. Fig. 7 illustrates an example of concentration maps and resulting profiles obtained. In accordance with EPMA measurements, aluminium profiles are similar to those of iron and do not show any accumulation. For the magnesium, higher concentration is visible on the periphery of nodules on the map and is confirmed on profiles. In comparison with EPMA analyses, SIMS allows getting better detection limit but with a lower spatial resolution (the graphite/matrix interface appears over a couple of microns on the profiles) and it remains a qualitative analysis.
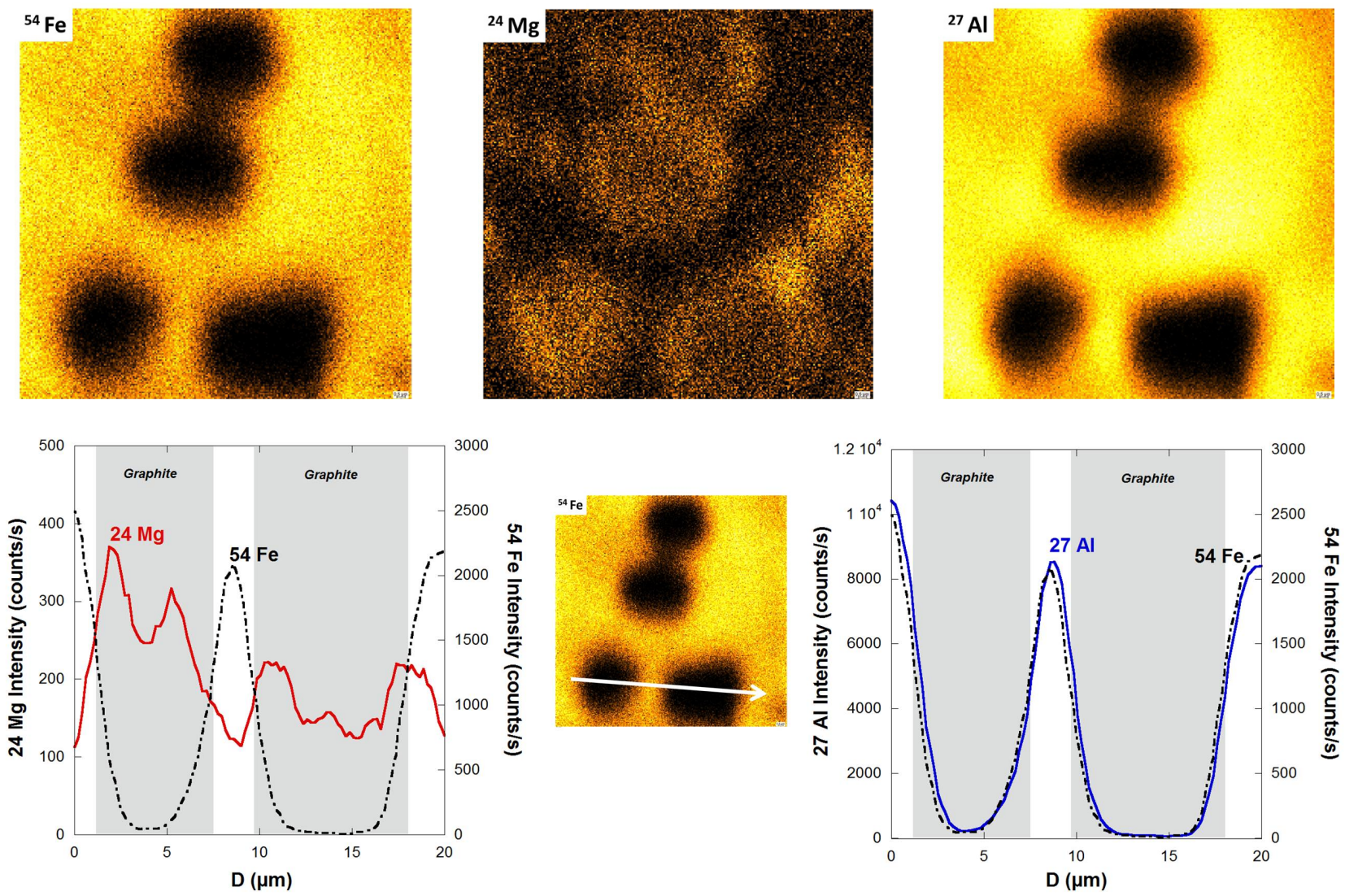

Figure 7. Concentration maps acquired by SIMS for iron, magnesium and aluminium around several nodules and resulting concentration profiles of magnesium and aluminium across two nodules. The size of the map is $30 \times 30 \mu \mathrm{m}^{2}$ and the higher the local content in element ( $\left.\mathrm{Fe}, \mathrm{Mg}, \mathrm{Al}\right)$ is, the higher is the intensity.

This increase in magnesium at the graphite/matrix interface has been already pointed out by Dierickx et al. in heat-treated spheroidal graphite cast iron samples [9]. It reinforces the hypothesis of an action of some trace element on graphite growth by an adsorption and/or absorption at the graphite surface during its growth. The present results suggest that $\mathrm{Mg}$ is adsorbed and then absorbed by graphite during rapid graphite growth, and then rejected during heat-treatment. On the 
contrary, aluminium certainly adsorbs at the graphite surface as it affects graphite growth, but does not seem to be absorbed as it would have been rejected as well. Finally, the fact that the same observations are made for reference and centrifugal castings consolidates the idea that the graphite growth proceeds according to the same mechanism during solidification and graphitization.

\section{Conclusion}

The impact of cooling rate and aluminium addition on graphite growth was studied for sand mould and centrifuged castings. OM and SEM observations from the present work together with previous TEM results strongly suggest that the growth mechanism of spheroidal graphite is the same during solidification and during graphitization by solid-state decomposition of cementite.

The addition of aluminium has been seen to promote a massive degeneracy of graphite shape in sand mould castings but not in the centrifuged ones. This confirms that high cooling rate during solidification promotes spheroidal growth of graphite and thus that the harmfulness threshold of elements like aluminium increases with cooling rate. However, it remains unclear why solid-state growth of graphite by decomposition of cementite is not affected by aluminium.

\section{Acknowledgment}

We are pleased to acknowledge D. Mangin (IJL, Université de Lorraine, Nancy, France) for SIMS analyses.

\section{References}

[1] ASM Specialty Handbook - Cast Irons. Ed J. R. Davis, 1996.

[2] H. Morrogh, Influence of some residual elements and their neutralization in magnesium-treated nodular cast iron, AFS Transactions 60 (1952) 439-451.

[3] H. Nieswaag, J. Zuithoff, Effect of S, P, Si and Al on the morphology and graphite structure of directionally solidified cast iron, Proc. $2^{\text {nd }}$ Internat. Symposium on the Metallurgy of Cast Iron (1976) 327-353.

[4] H. M. Muhmond, H. Fredriksson, Graphite growth control analysis in high Al cast iron, International Journal of Cast Metals Research 29 (2016) 272-278.

[5] J. Fargues, J. C. Margerie, Obtention de pièces minces en fonte GS spéciale à l'aluminium, Fonderie - Fondeur d'aujourd'hui 42 (1985) 23-35.

[6] K. Theuwissen, J. Lacaze, L. Laffont, Structure of graphite precipitates in cast iron, Carbon 96 (2016) 1120-1128.

[7] K. Theuwissen, M.C. Lafont, L. Laffont, B. Viguier, J. Lacaze, Microstructural characterization of graphite spheroids in ductile iron, Trans. Indian Inst. Metals 65 (2012) 627-631.

[8] R. Jday, L. Laffont, J. Lacaze, An electron microscopy study of graphite growth in nodular cast irons, submitted to Materials Characterization.

[9] P. Dierickx, C. Verdu, A. Reynaud, R. Fougères, A study of physico-chemical mechanisms responsible for damage of heat-treated and as-cast ferritic spheroidal graphite cast irons, Scr. Mater. 34 (1996) 261-268. 